\section{International Scientific Journal Theoretical \& Applied Science}

\author{
p-ISSN: 2308-4944 (print) e-ISSN: 2409-0085 (online) \\ Year: 2015 Issue: 04 Volume: 24
}

Published: $30.04 .2015 \quad$ http://T-Science.org
Natalia Vladimirovna Batciun

Associate Professor,

Department of World Economy,

Irkutsk National Research Technical University,

Russia

nbatsun@mail.ru

SECTION 31. Economic research, finance,

innovation, risk management.

\title{
BUSINESS AND ECOLOGY: CONTRADICTIONS AND ADDITIONAL OPPORTUNITIES
}

Abstract: No society has by now found reliable instruments of harmonizing of the relations of mankind with environment, or, speaking in other words, managing ecological aspects of quality of life. The opened, competing markets, promote introduction of innovations and increase of economic efficiency, thus create conditions for improvement of quality of life of all population.

Key words: ecological business, ecological marketing, ecological marks, economic benefit, competitiveness.

Language: Russian

Citation: Batciun NV (2015) BUSINESS AND ECOLOGY: CONTRADICTIONS AND ADDITIONAL OPPORTUNITIES. ISJ Theoretical \& Applied Science 04 (24): 247-251.

Soi: http://s-o-i.org/1.1/TAS*04(24)45 Doi: crossef http://dx.doi.org/10.15863/TAS.2015.04.24.45

\section{БИЗНЕС И ЭКОЛОГИЯ: ПРОТИВОРЕЧИЯ И ДОПОЛНИТЕЛЬНЫЕ ВОЗМОЖНОСТИ}

Аннотация: Как известно, пока что ни в одном обществе не найдены надёжные инструменты гармонизации отношений человечества с природной средой, или, говоря иными словами, управления экологическими аспектами качества жизни. Крупнейшие участники мирового экономического рынка, соблюдают в своей деятельности принцииь экологического и сочиального характера.

Ключевые слова: экологический бизнес, экологический маркетинг, экологическая маркировка, экономический эффект, конкурентоспособность.

Между бизнесом и экологией существуют противоречия, в силу которых предпринимательская деятельность характеризуется в основном нерациональным использованием ресурсов и высокой степенью загрязнения окружающей среды. Необходимы инновационные стратегии, к числу которых относятся экобизнес и экомаркетинг. Понятие экобизнеса в самом общем смысле объединяет различные виды деятельности: внедрение на предприятиях технологий и методов, направленных на сокращение ущерба; производство приборов для измерения экологической нагрузки; производство природоохранного оборудования для уменьшения экологической нагрузки; разработку экологизационных технологий; консультационные и иные услуги в этой области.
В качестве критериев отнесения предприятий и организаций к экологически ориентированным выделяются [1]:

- закрепление в уставе организации как основной цели деятельности - осуществление работ и услуг, а также производство продукции природоохранного назначения;

- выполнение в рамках реализации федеральных и региональных экологических и природно-ресуреных программ государственного и муниципального заказа;

- выпуск продукции, осуществление работ и услуг, отвечающих потребностям природоохранной и ресурсовосстановительной деятельности;

- преобладание удельного веса продукции, работ и услуг природоохранного назначения в общем объеме производства. 
Impact Factor ISRA (India) $\quad=\mathbf{1 . 3 4 4}$

Impact Factor ISI (Dubai, UAE) $=\mathbf{0 . 8 2 9}$

based on International Citation Report (ICR)

Impact Factor GIF (Australia) $\quad \mathbf{0} \mathbf{0 . 3 5 6}$
Impact Factor JIF $\quad=\mathbf{1 . 5 0 0}$

Impact Factor SIS (USA) $\quad=0.912$

Impact Factor РИНЦ (Russia) $=\mathbf{0 . 1 7 9}$

Impact Factor ESJI (KZ) $\quad=\mathbf{1 . 0 4 2}$
Современный мировой рынок экологических товаров и услуг постоянно растет. По данным Международной федерации движений за органическое земледелие (International Federation of Organic Agriculture Movements IFOAM), при дальнейшей динамике роста мировой рынок экопродуктов к 2020 году может достичь \$ 200-250 млрд. [2]

Предполагается, что компании, раньше других осознавшие и заложившие в свои стратегии новые возможности использования экологической составляющей бизнеса, получат реальные преимущества. Решение экологических проблем зачастую может объективно способствовать появлению новых возможностей и получению предприятиями новых выгод:

- дополнительные возможности для развития деловой активности;

- повышение конкурентных преимуществ: фирмы, ранее других осуществившие капиталовложения в экологически чистые технологии, становятся лидерами, прежде всего на внутреннем рынке;

- аналогичный эффект на мировом рынке для стран, ранее других осуществивших капиталовложения в экологически чистые технологии;

- защищенность передового экологически ориентированного бизнеса от иностранной конкуренции;

- выгоды в конкурентной борьбе за рынки сбыта благодаря использованию темы экологичности товаров.

Как показывает опыт, предприятия начинают заботиться о снижении своего отрицательного воздействия на окружающую среду в трех случаях:

во-первых, когда владельцы и руководство компаний становятся более экологически сознательными и начинают принимать во внимание воздействие их бизнеса и производства на природу;

во-вторых, когда юридические нормы, контроль за соблюдением которых эффективно осуществляется государством, настолько ужесточаются, что предприятиям становится экономически выгодно их соблюдать;

в-третьих, когда важные для компании общественные группы начинают учитывать экологичность как самого продукта, так и его производства, использования и утилизации при принятии решений о покупке, инвестировании и т.д., то есть когда экологически ответственное поведение создает для бизнеса отчетливые конкурентные преимущества. Таким образом, надлежащая государственная политика обусловливает экономический эффект, который может извлечь фирма при экологизации бизнеса. Это фактически маркетинг административных органов, носящий некоммерческий характер.

Маркетинговая функция государственных и региональных органов здесь заключается, вопервых, в том, чтобы установить соответствующие нормативы, следить за их соблюдением и использовать систему наказаний; во-вторых, в пропаганде среди предпринимателей экологичных технологий и разъяснении их экономической эффективности. Примером может служить реализация мероприятий федеральной целевой программы «Охрана озера Байкал и социально-экономическое развитие Байкальской природной территории на 2012-2020 годы» (ФЦП). Согласно программы Иркутской области из федерального бюджета планируется выделить 12,4 миллиарда рублей. Средства будут направлены на модернизацию, реконструкцию комплексов очистных сооружений и систем водоотведения, строительство мусоросортировочных станций и полигонов ТБО на территории региона[3]. В современной России управление отходами сводится к организации (в городах) контейнерного сбора отходов и их своевременного удаления с мест образования. В городе образуется один поток отходов. При этом вопрос, куда этот поток направлять - на захоронение или сжигание, решается в зависимости от местных технических условий. Сортировка практически не производится.

В ряде российских городов в целях выделения вторсырья построены установки для ручной сортировки всей образующейся неподготовленной массы твёрдых отходов. Однако, как показывает практика, выход сырья в таких условиях составляет всего 5-8\% (редко 10$15 \%)$, что не покрывает даже эксплуатационные затраты [4].

Эколого-экономическую потребность можно охарактеризовать как потребность в таком взаимодействии со средой, в процессе ее хозяйственного использования, которое не нарушало бы ее жизнепригодности, обеспечивающей условия хозяйственного развития и сохранения здоровья человека [5].

Однако есть и другой экологический маркетинг, проводимый самою фирмой, которая экологизирует свой бизнес, подстраиваясь под спрос потребителей. Это происходит, когда важные для фирмы общественные группы начинают учитывать экологичность как самого продукта, так и его производства, использования и утилизации при принятии решений о покупке, инвестировании, пиаре и т.д., то есть когда экологически ответственное поведение создает для бизнеса отчетливые конкурентные преимущества. 
Одним из инструментов такого маркетинга служит внедрение системы экологического маркирования продукции. Экологическая маркировка является для потребителя своеобразным носителем информации об уровне экологической безопасности и чистоты товара, об экологическом воздействии в результате производства или использования продукта.

Применение экомаркировки носит добровольный характер, но для рынков отдельных видов продукции она становится важным фактором конкуренции. Например, применительно к продуктам питания предъявляются особые требования безопасности, в том числе и экологические, так как их «экологическая чистота» оказывает непосредственное воздействие на здоровье потребителя, и именно этот фактор может стать определяющим в конкурентоспособности товара.

Среди общей совокупности знаков выделяются знаки двух подгрупп. Первая подгруппа информирует об экологической чистоте товара, о безопасности продукции или отдельных её свойств для жизни, здоровья, имущества потребителей и окружающей среды. К ней относятся такие экологические знаки, как «Белый лебедь» (Скандинавские страны), «Голубой ангел» (Германия), «Экологический выбор» (Канада), зелено-голубой цветок стилизованное изображение одуванчика - значок экологического соответствия, принятый в странах EC. Экознак японской ассоциации по охране окружающей среды информирует о том, что данное изделие минимально загрязняет и разрушает окружающую среду. Имеется подобный знак и в России[6].

Проблема формирования экологически ответственного потребителя в России ещё далеко не решена. К основным мотивам употребления (покупки) экологичных продуктов питания является их полезность для организма человека. Но нельзя забывать и такой основной барьер покупки как высокая цена. Еще одним ограничением является недостаточная информированность населения о полезности этих продуктов. Стимулирующими факторами употребления экологически чистых продуктов являются: рост доходов населения, активная забота о здоровье. Быть здоровым гораздо выгоднее с экономической точки зрения, к этому нас склоняют и увеличение платных медицинских услуг. Естественно, возникает вопрос: а не слишком ли бедно население России, чтобы позволить себе выбирать экологически лучшие продукты, если они будут стоить дороже? Тем не менее, социальная база для формирования экологически чувствительного потребительского рынка в России на основе нового среднего класса, безусловно, имеется. Конечно, в России более 40 млн. людей живут за чертой бедности, и вряд ли они смогут потреблять экологически лучше продукты, если те будут дороже обычных (но даже люди с низким денежным доходом могут выключать свет, когда он им не нужен, и экономить на плате за электричество). Вместе с тем на 20\% самых богатых людей страны приходится 47\% всех денежных доходов [7].

Организация сама должна заботиться о сохранении конкурентоспособности и прибыли, для этого она прогнозирует развитие рыночной ситуации, анализирует появление различных предпосылок, способных изменить существующие рыночное равновесие. Экологизация бизнеса может, происходит через принятие корпоративных экологических кодексов, коллективной ответственности и взаимопомощи в сфере защиты окружающей среды и живой природы. Целью корпоративных экологических кодексов является создание отраслевых систем экологического регулирования деятельности для обеспечения устойчивости развития и получения выгод от минимизации негативных последствий для природы. Согласно Й. Шумпетеру именно предприниматель является движущей силой экономического развития. Благодаря его организаторским способностям, интуиции, способности к риску экономика получает стимул к совершенствованию [8].

Как известно, пока что ни в одном обществе не найдены надёжные инструменты гармонизации отношений человечества с природной средой, или, говоря иными словами, управления экологическими аспектами экономической жизни человека.

Такая формулировка проблемы подсказывает, что для упомянутого управления можно попробовать использовать методы одной концепции, взятой из совсем другой сферы. Это концепция Всеобщего менеджмента качества, которая становится во всём мире всё более популярной, являясь своего рода развитием маркетинговой концепции управления бизнесом.

Система менеджмента качества (СМК) - это экономически выгодная система управления организацией, прежде всего для самого предприятия при работе в условиях конкурентной борьбы. Теория и практика СМК достаточно разработаны, во многом формализованы и, хотя предназначены в основном для повышения эффективности работы предприятия, с успехом применяются и в непроизводственной сфере, в некоммерческих организациях [9].

Она определяет главным принципом ориентацию на потребителя. СМК - это система, создаваемая на предприятии для постоянного 
формирования политики и целей в области качества, а также для достижения этих целей. Система качества:

- уменьшает внутренние потери сырья, материалов, рабочего времени;

- позволяет на основе применения статистических методов увеличивать объем продаж из того количества сырья и при меньшем количестве труда;

- находит и устраняет не нужные, дублированные потоки информации;

- обеспечивает управляемость персоналом;

- повышает ответственность и дисциплинированность персонала;

- меняет менталитет персонала;

- позволяет управлять себестоимостью;

- позволяет руководителю сфокусировать усилия персонала на ключевых процессах: маркетинг, качество производства, увеличение объема продаж;

- обеспечивает имидж руководителю, предприятию, продукции, что очень важно для присутствия на рынке в первых рядах;

- дает обоснованную уверенность в возможностях фирмы.

Главным содержанием её методологии является ответственность всех работников не только за качество продукции и услуг на всех стадиях разработки, создания и использования, но и за качество функционирования предприятия в целом. Эффективная система менеджмента качества позволяет также снизить затраты на управление: документированность ключевых процессов деятельности компании обеспечивает их лучшую управляемость; контроль, анализ и пересмотр процессов обеспечивает их непрерывное совершенствование; распределение полномочий и ответственности персонала дает механизмы контроля исполнения обязанностей и меры предупреждения отрицательных результатов.

Возможен разный подход к сертификации продукции. Можно оценивать продукт как конечный результат производства - и можно оценивать само производство и уровень его воздействия на окружающую среду, учитывая все этапы: добыча сырья, собственно производство, логистика, утилизация, т.е. полный цикл. Последний вариант больше соответствует идеологии концепции управления качеством.

В России на государственном уровне до сих пор не определено, что значит термин «экологический». В настоящее время каждый желающий может маркировать свою продукцию как «экологическую», «биологическую», «органическую», не неся перед потребителем каких-либо дополнительных обязательств, чем многие с успехом пользуются для получения конкурентных преимуществ на рынке.

С точки зрения качества жизни это означает ориентацию в экологической политике на гуманистические показатели, экологизацию производственных процессов (включая систему стандартов), потребления и общественного сознания. Социально-экологическая ответственность и рейтинги российского бизнеса уже не является новинкой. Рейтинги составляются уже с 2007 года и их результаты общедоступны.[10]. Во многих странах корпоративное регулирование экологически ответственного поведения бизнеса уже является нормой.

\section{References:}

1. Boboshko VI (2006) Osobennosti ekologicheski orientirovannogo malogo predprinima-telstva $\mathrm{v}$ Rossii / V.I. Boboshko, A.A. Gusev, I.M. Potravnyj / Ekonomika prirodo-polzovaniya. 2006. - №5.

2. (2013) RUSSIAN FOOD\&DRINKS MARKET MAGAZINE №4/2013. Available: http://www.foodmarket.spb.ru/current.php?artic le=1851 (Accessed: 25.04.2015).

3. (2015) Irkutskaya oblast oficialnyj portal. Available: $\quad$ http://irkobl.ru/events/787195/ (Accessed: 25.04.2015).
4. Nikogosov X (2010) Razdelnyj sbor tverdyx bytovyx otxodov / X. Nikogosov, $\mathrm{M}$. Bochkova, S.Malceva. / Kommunalshhik.2010.-№ 11.

5. Suxorukova SM (2015) Ekonomika i ekologiya (politekonomicheskij aspekt) / S.M. Suxorukova. Available: http://lib4all.ru/base/B2456/B2456Content.php \# (Accessed: 25.04.2015).

6. (2015) Mediaresurs. Available: EcoRussia.info http://www.ecorussia.info/ru/ecopedia/ecomarki rovka (Accessed: 25.04.2015). 
Impact Factor ISRA (India) $\quad=\mathbf{1 . 3 4 4}$

Impact Factor ISI (Dubai, UAE) $=\mathbf{0 . 8 2 9}$

based on International Citation Report (ICR)

Impact Factor GIF (Australia) $\quad \mathbf{0} \mathbf{0 . 3 5 6}$ $\begin{array}{lr}\text { Impact Factor JIF } & =\mathbf{1 . 5 0 0} \\ \text { Impact Factor SIS (USA) } & =\mathbf{0 . 9 1 2} \\ \text { Impact Factor PИHЦ (Russia) } & =\mathbf{0 . 1 7 9} \\ \text { Impact Factor ESJI (KZ) } & =\mathbf{1 . 0 4 2}\end{array}$

tonomova]. - 4-e izd. - Moscow: Direktmedia Pablishing.

10. Kotler F (2007) Strategicheskij marketing nekommercheskix organizacij / F. Kotler, A.P.Andersen. - Izd. 6-e. - Rostov n/D: Feniks.

11. Socio-environmental responsibility and the ratings of Russian business. Available: http://www.biodat.ru/db/mon/rating.htm (Accessed: 25.04.2015). 